Jurnal Abdidas Volume 2 Nomor 6 Tahun 2021 Halaman 1295 - 1300

JURNAL ABDIDAS

http://abdidas.org/index.php/abdidas

\title{
Sosialisasi Manajemen Strategi Pemasaran Produk Air Minum Kemasan “Wk Siompu” BUMDes Karongo Desa Wakinamboro Kec. Siompu Kab. Buton Selatan
}

\author{
La Sudarman ${ }^{1 \bowtie}$, Murni Sari $^{2}$, Ahmad Amiruddin $^{3}$ \\ D4 Manajemen Pemasaran Internasional, Politeknik Baubau, Indonesia ${ }^{1}$ \\ D4 Keuangan Publik, Politeknik Baubau, Indonesia ${ }^{2}$ \\ Manajemen Informasi Rekam Medis, Politeknik Baubau, Indonesia ${ }^{3}$ \\ E-mail : sudarmanla132@gmail.com ${ }^{1}, \underline{\text { murnisari584@gmail.com }}{ }^{2}$, \\ ahmadamiruddinpoltekbaubau@gmail.com
}

\begin{abstract}
Abstrak
Usaha Mikro Kecil dan Menengah (UMKM) "Air Kemasan WK Siompu”, yang merupakan Badan Usaha Milik Desa (BUMDes) yang ada di Wakinamboro berperan penting dalam pembangunan ekonomi nasional. Selain berperan dalam pertumbuhan ekonomi juga berperan dalam penyerapan tenaga kerja. UMKM ini jika sudah beroperasi diharapkan mampu bersaing dengan produk air mineral kemasan yang sudah lama eksis di masyarakat. Untuk meningkatkan daya saing produk air kemasan "WK Siompu" maka diperlukan strategi khusus untuk memasarkan produk tersebut. Strategi yang dimaksud adalah manajemen strategi pemasaran produk 4 P yang akan memberikan solusi melalui kegiatan Pengabdian kepada Masyarakat. Metode kegiatan pengabdian ini adalah metode pelatihan yang terdiri dari: fokus diskusi kelompok, penyusunan materi sosialisasi, sosialisasi manajemen strategi pemasaran, evaluasi kegiatan dan penyusunan laporan kegiatan. Kegiatan sosialisasi ini dibagi dalam tiga tahap yakni tahap registrasi peserta, proses pelaksanaan dan tahap akhir kegiatan. Hasil yang dicapai adalah peserta diharapkan mampu menerapkan manajemen strategi pemasaran $4 \mathrm{P}$ jika produk air minum kemasan telah diproduksi secara masal. Kegiatan ini selain memberikan tambahan pengetahuan, juga memberikan cara mengaplikasikan manajemen strategi pemasaran produk $4 \mathrm{P}$ dalam pemasaran produk air kemasan "WK Siompu".
\end{abstract}

Kata Kunci: strategi pemasaran, WK Siompu, bauran pemasaran

\begin{abstract}
Micro, Small and Medium Enterprises (UMKM) “WK Siompu Bottled Water”, which is a Village Owned Enterprise (BUMDes) in Wakinamboro has an important role in national economic development. In addition to playing a role in economic growth, it also plays a role in employment. If this UMKM are operational, they are expected to be able to compete with bottled mineral water products that have long existed in the community. To increase the competitiveness of "WK Siompu" bottled water products, a special strategy is needed to market these products. The strategy in question is the management of the 4 P product marketing strategy which will provide solutions through Community Service activities. The method of this service activity is a training method which consists of: focus group discussions, preparation of socialization materials, socialization of marketing strategy management, evaluation of activities and preparation of activity reports. This socialization activity is divided into three stages, namely the participant registration stage, the implementation process and the final stage of the activity. The result achieved is that participants are expected to be able to implement the 4 P marketing strategy management if bottled water products have been mass produced. This activity in addition to providing additional knowledge, also provides ways to apply the management of the 4P product marketing strategy in the marketing of "WK Siompu" bottled water products.
\end{abstract} Keywords: marketing strategy, WK Siompu, marketing mix

Copyright (c) 2021 La Sudarman, Murni Sari, Ahmad Amiruddin

$\triangle$ Corresponding author

Address : Politeknik Baubau

Email : sudarmanla132@gmail.com

DOI : https://doi.org/10.31004/abdidas.v2i6.468

ISSN 2721-9224 (Media Cetak)

ISSN 2721- 9216 (Media Online) 
1296 Sosialisasi Manajemen Strategi Pemasaran Produk Air Minum Kemasan “Wk Siompu” BUMDes Karongo Desa Wakinamboro Kec. Siompu Kab. Buton Selatan - La Sudarman, Murni Sari, Ahmad Amiruddin

DOI: https://doi.org/10.31004/abdidas.v2i6.468

\section{PENDAHULUAN}

Manajemen strategi (strategic management) menurut Hunger J David \& Thomas L Wheelen dalam bukunya berjudul Manajemen Strategis hasil alih bahasa oleh (Hunger \& Agung, 2003) dari judul aslinya: Strategic Management adalah serangkaian keputusan dan tindakan manajerial yang menentukan kinerja perusahaan dalam jangka panjang. Sedangkan menurut Fred R David dalam bukunya berjudul Strategic Management Concepts diterjemahkan dalam bahasa Indonesia oleh Ahmad Lukman \& Melvi 2003: 5, dalam Juwono, 2012) dapat didefinisikan sebagai ilmu tentang perumusan, pelaksanaan, dan evaluasi keputusankeputusan lintas fungsi yang memungkinkan organisasi mencapai tujuannya.

Manajemen strategi pemasaran merupakan perencanaan strategi yang berorientasi pada jangkauan masa depan yang jauh (disebut visi) dan ditetapkan sebagai keputusan yang bersifat mendasar dan prinsipal agar memungkinkan suatu organisasi berinteraksi secara efektif (disebut misi), dalam usaha menyelesaikan sesuatu (perencanaan operasional untuk menghasilkan benda serta ataupun jasa pelayanan) yang bermutu, dengan ditunjukkan pada optimalisasi pencapaian tujuan (disebut tujuan strategis) dan berbagai sasaran organisasi. Begitu banyak pengertian manajemen strategi, namun pada dasarnya manajemen strategi merupakan suatu sistem yang sebagai suatu kesatuan memiliki berbagai komponen yang saling berhubungan dan mempengaruhi (Setiawan, 2018 dalam Wijandari $\&$ Sumilah, 2021).

Bauran pemasaran adalah sebagai berikut: "Bauran pemasaran adalah perangkat alat pemasaran yang digunakan perusahaan untuk mengejar tujuan perusahaannya”. Maka, dapat disimpulkan bahwa bauran pemasaran merupakan satu perangkat yang terdiri dari produk, harga, promosi, dan distribusi, yang di dalamnya akan menentukan tingkat keberhasilan pemasaran dan semua itu ditujukan untuk mendapatkan respon yang diinginkan dari pasar sasaran. (Kotler dan Keller, 2007 dalam Mas'ari Et Al., 2020)). Sedangkan menurut (Saladin dan Oesman, 2002 dalam Mas'ari et al., 2020), bauran pemasaran adalah serangkaian dari variabel pemasaran yang dapat dikuasai oleh perusahaan dan digunakan untuk mencapai tujuan dalam pasar sasaran. (Kotler dan Armstrong, 2001 dalam Mas'ari et al., 2020) menyatakan bahwa bauran pemasaran sebagai perangkat alat pemasaran taktis dan terkontrol yang dipadukan oleh perusahaan untuk menghasilkan respon yang diinginkan pasar sasaran.

Salah satu kelemahan pengusaha/ badan usaha adalah dalam bidang strategi. Strategi merupakan alat yang sangat penting bagi kemajuan suatu perusahaan. Setiap perusahaan yang bersaing dalam suatu industri pasti mempunyai strategi bersaing. Dalam perubahan pola persaingan yang sangat ketat ini, strategi suatu perusahaan harus disesuaikan atau bahkan diubah untuk memperoleh peluang-peluang serta menghindari ancaman dari para pesaing (Kasmir, 2012 dalam Wijandari \& Sumilah, 2021). Rendahnya strategi yang dimiliki oleh para pelaku usaha menjadi hal yang buruk untuk kemajuan usaha yang digelutinya, dengan strategi pemasaran yang menggunakan media promosi baik online maupun offline (mouth to mouth) akan menjadi salah satu strategi yang bisa diandalkan oleh Badan Usaha Milik Desa (BUMDes) khususnya di Desa Wakinamboro Kecamatan Siompu Kab. Buton Selatan dalam memasarkan produk air kemasan "WK Siompu".

Berdasarkan hasil diskusi bersama pengelola BumDes Karongo, belum ada sosialisas/ pelatihan 
1297 Sosialisasi Manajemen Strategi Pemasaran Produk Air Minum Kemasan "Wk Siompu” BUMDes Karongo Desa Wakinamboro Kec. Siompu Kab. Buton Selatan - La Sudarman, Murni Sari, Ahmad Amiruddin

DOI: https://doi.org/10.31004/abdidas.v2i6.468

mengenai strategi pemasaran produk. Dengan melihat kondisi dan keadaan produk yang dihasilkan masih terbilang baru mulai beroperasi, maka kami berinisiatif untuk melakukan kegiatan berupa sosialisasi manajemen strategi pemasaran produk "wk siompu" kepada pengelola Bumdes Karongo. Kegiatan ini bertujuan untuk memberikan memahami konsep dan implementasi manajemen strategi pemasaran, mampu menyusun rencana pemasaran produk air kemasan yang efektif dan efisien, serta peserta mampu mengaplikasikan 4 bauran pemasaran (4 P) yakni produk, price, promotion dan distribution, dalam memasarkan produk air kemasan "WK Siompu".

\section{METODE}

Metode yang digunakan dalam kegiatan ini adalah metode pelatihan. Waktu pelaksanaan tanggal 7 dan 8 November 2021, lokasi kegiatan dilaksanakan di Balai Desa Wakinamboro Kec. Siompu Kab. Buton Selatan. Sasaran kegiatan adalah pengelola Bumdes Karongo dan beberap tokoh masyarakat. Adapun langkah-langkah kegiatan Pengabdian kepada Masyarakat adalah sebagai berikut :

1) Fokus Diskusi Kelompok, dimana untuk tahapan ini pengabdi dengan pengelola BUMDes Karongo Air Minum Kemasan "WK" Desa Wakinamboro untuk menemukan kebutuhan sosialisasi. Karena jarak lokasi pengabdian yang cukup jauh maka kegiatan FDK dilaksanakan sesuai rancangan kegiatan pada awal bulan Oktober 2021.

2) Penyusunan Materi Sosialisasi. Pengabdi menyusun materi yang dibutuhkan dalam Pengabdian yang telah disepakati bersama dengan ruang lingkup materi sosialisasi sebagai berikut :

$>$ Konsep Strategi
$>$ Strategi Manajemen Pemasaran

> Bauran Pemasaran 4 P (Produk, Price, Promotion, Place).

Materi dirancang setelah kegiatan FDK dari minggu kedua bulan Oktober s/d awal minggu pertama bulan November.

3) Sosialisasi Manajemen Strategi Pemasaran Air Minum Kemasan "WK Siompu” Desa Wakinamboro.

Sosialisasi kegiatan ini dilaksanakan pada awal minggu pertama November selama 2 hari, tanggal 7 dan 8 November 2021. Dengan rincian, tanggal 7 November 2021 pertemuan dengan Kepala Desa dan membahas pemantapan persiapan kegiatan esok harinya. Tanggal 8 November 2021 pelaksanaan kegiatan sosialisasi.

4) Evaluasi kegiatan, bertujuan untuk melihat kesesuaian pelaksanaan kegiatan dengan rencana yang telah dibuat.

5) Penyusunan laporan kegiatan PkM, sebagai bentuk laporan pertanggungjawaban kegiatan kepada Politeknik Baubau. Penyusunan Laporan Kegiatan dilaksanakan setelah selesai kegiatan.

\section{HASIL DAN PEMBAHASAN}

Kegiatan ini diikuti oleh pengelola Bumdes Karongo dan beberapa masyarakat Desa Wakinamboro Kec. Siompu Kab. Buton Selatan yang sempat hadir yang berjumlah sekitar 30 orang. Kegiatan Sosialisai berlangsung selama satu hari. Dengan cakupan materi berupa: konsep strategi, strategi manajemen pemasaran dan bauran pemasaran.

Dalam kegiatan pelatihan, kegiatan dilakukan dalam 3 tahap diantaranya : 
1298 Sosialisasi Manajemen Strategi Pemasaran Produk Air Minum Kemasan “Wk Siompu” BUMDes Karongo Desa Wakinamboro Kec. Siompu Kab. Buton Selatan - La Sudarman, Murni Sari, Ahmad Amiruddin

DOI: https://doi.org/10.31004/abdidas.v2i6.468

\section{Tahap Registrasi Peserta}

Kegiatan dimulai dengan registrasi peserta. Hal ini bertujuan untuk mengetahui secara pasti total jumlah peserta yang ikut dalam kegiatan ini, keteraturan peserta serta jumlah pasti pengelola Bumdes dan masyarakat yang hadir dalam menyukseskan kegiatan ini. Jumla peserta yang hadir berjumlah 30 orang yang terdiri dari 10 orang pengelola Bumdes dan 20 orang tokoh masyarakat.

\section{Pelaksanaann Kegiatan}

Pada tahapan ini ada beberapa kegiatan yang dilaksanakan selama satu hari, dengan urutan kegiatan sebagai berikut :

1. Memberikan materi berupa Manajemen Strategi Pemasan Air Minum Kemasan "WK Siompu".

Materi disampaikan oleh Ketua Tim Pengabdian dengan memberikan konsepkonsep manajemen strategi pemasaran berupa ilmu tentang perumusan, pelaksanaan dan keputusan-keputusan yang berkaitan dengan pemasaran.

2. Memberikan materi berupa konsep Bauran Pemasan 4P.

Konsep bauran pemasaran atau yang sering dikenal dengan marketing mix yang disampaikan kepada peserta adalah konsep bauran pemasaran 4P, yakni :

Product, adalah sesuatu yang ditawarkan kedalam pasar untuk diperhatikan, dimiliki, dipakai atau dikonsumsi sehingga dapat memuaskan keinginan atau kebutuhan. Produk yang dimaksud dalam kegiatan ini adalah "Air Minum Kemasan".

Price, adalah harga sejumlah uang yang dibayarkan untuk memperoleh barang atau jasa yang diinginkan. Harga yang dimaksud adalah penetapan harga jual produk air minum kemasan "WK Siompu".

Promotion, adalah unsur dalam bauran-bauran pemasaran perusahaan bisnis yang digunakan untuk memberi tahu, membujuk dan mengingatkan tentang produk suatu perusahaan. Promosi yang bisa dilakukan dalam hal ini adalah dengan mengunakan media cetak seperti brosur, pamphlet, spanduk, leafnet dan sebagainya. Atau promosi melalui media social melalui facebook, instagram, whatsapp atau website yang digunakan untuk memasarkan produk "WK Siompu".

Place, lokasi adalah tempat pasar potensial produk air kemasan "WK Siompu". Mencari pasar potensial selain di luar Pulau Siompu bertujuan untuk memperluas pangsa pasar.

3. Diskusi dan tanya jawab yang dipandu oleh moderator.

Kegiatan diskusi dilaksanakan setelah pemateri telah menyampaikan materi mengenai manajemen strategi pemasaran. Kegiatan ini dipandu oleh anggota pengabdi sebagai moderator. Jumlah pertanyaan dibatasi sebanyak 5 pertanyaan dan berkaitan erat dengan konsep manajemen strategi dan bauran pemasaran 4P. Dari kegiatan diskusi terjadi sharing ilmu dan pengalaman, terlihat peserta antusias baik mengajukan pertanyaan maupun memberikan tanggapan

\section{Tahap Akhir Kegiatan}

Pada tahap ini kegiatan yang dilakukan adalah mengevaluasi kegian Dari hasil evaluasi kegiatan ditemukan bahwa pelaksanaan kegiatan sudah sesuai dengan tahapan-tahapan kegiatan 
1299 Sosialisasi Manajemen Strategi Pemasaran Produk Air Minum Kemasan “Wk Siompu” BUMDes Karongo Desa Wakinamboro Kec. Siompu Kab. Buton Selatan - La Sudarman, Murni Sari, Ahmad Amiruddin

DOI: https://doi.org/10.31004/abdidas.v2i6.468

yang direncanakan. Adapun tujuan dari kegiatan ada 2 yaitu:

a) Memberikan pemahaman tentang konsep manajemen strategi, hal ini bisa diukur dengan. Dari hasil evaluasi yang dilakukan ditemukan bahwa peserta bisa memahami konsep manajemen strategi pemasaran.

b) Aplikasi/ penerapan bauran pemasaran. Hal ini belum terukur karena produk air minum kemasan "WK Siompu" belum diproduksi secara masal. Hasil evaluasi bisa diukur jika produk sudah mulai diproduksi dan dipasarkan dengan ketentuan bahwa tujuan kegiatan tercapai apabila dalam proses pemasarannya sudah menerapkan bauran 4P. kegiatan evaluasi penerapan bauran 4P direncanakan akan dilaksanakan ketika Bumdes telah beroperasi.

Manfaat yang dapat dirasakan dari kegiatan ini adalah adanya sharing ilmu pengetahuan tentang manajemen strategi pemasaran produk, penetapan harga produk, melakukan promosi dengan memanfaatkan media cetak dan elektronik, dan mencari lokasi pasar potensial di luar Pulau Siompu sehingga mampu bersaing dengan produkproduk air kemasan lainnya.

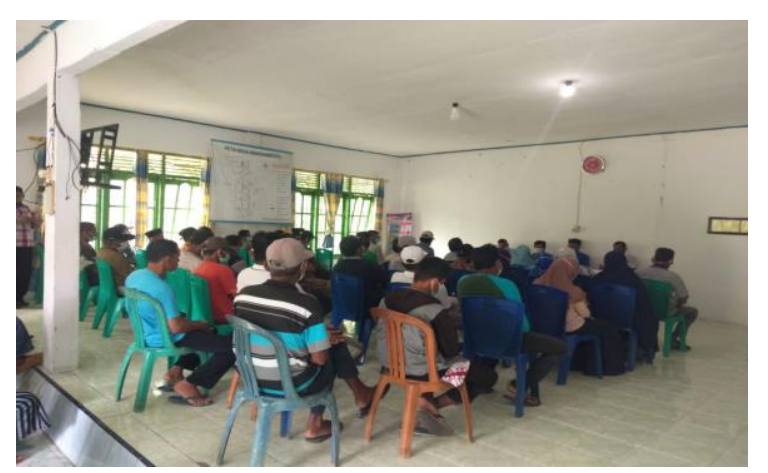

Gambar 1. Peserta Sosialisasi Manajemen Strategi Pemasaran Air Kemasan "WK Siompu

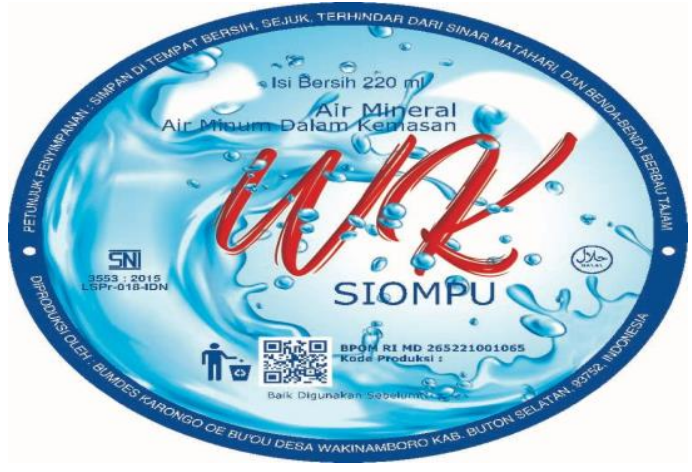

Gambar 2. Kemasan Produk Air Kemasan "WK Siompu"

\section{SIMPULAN}

Kegiatan sosialisasi stretegi pemasaran produk air kemasan "WK Siompu" BumDes Wakinamboro memberikan tambahan pengetahuan tentang strategi dalam memasarkan produk air kemasan. Produk air kemasan "WK Siompu" yang akan segera diproduksi secara masal diharapkan dapat mampu bersaing dengan produk air kemasan lainnya yang sudah terjun di pasar seperi merekmerek yang sudah terkenal baik air kemasan lokal maupun nasional. Pengetahuan tentang manajemen strategi pemasaran diharapkan mampu menjadi modal bagi pengelola Bumdes Karongo Desa Wakinamboro Kec. Siompu dalam memasarkan produknya nanti.

\section{UCAPAN TERIMA KASIH}

Terima kasih kepada Kepala Desa Wakinamboro beserta para peserta kegiatan yang telah meluangkan waktunya untuk mengikuti kegiatan ini dengan penuh semangat, serta memberikan kesempatan kepada kami Tim Dosen Politeknik Baubau dalam melaksanakan kegiatan pengabdian ini.

\section{DAFTAR PUSTAKA}

Hunger, J. D. + T. L. W. Dalam J., \& Agung. (2003). Analisis Manajemen Strategik Perusahaan Waralaba (Franchise) (Studi Kasus Di Restoran Cepat Saji Mcdonald's) Periode Oktober - Desember 2011. 
1300 Sosialisasi Manajemen Strategi Pemasaran Produk Air Minum Kemasan “Wk Siompu” BUMDes Karongo Desa Wakinamboro Kec. Siompu Kab. Buton Selatan - La Sudarman, Murni Sari, Ahmad Amiruddin

DOI: https://doi.org/10.31004/abdidas.v2i6.468

Juwono, O. (2012). Analisis Manajemen Strategik Perusahaan Waralaba (Franchise) (Studi Kasus Di Restoran Cepat Saji Mcdonald's). Jurnal Ekonomika Dan Manajemen, 1(1), 121. Http://Journal.Budiluhur.Ac.Id/Index.Php/E $\mathrm{ma} /$ Article/View/278

Mas'ari, A., Hamdy, M. I., \& Safira, M. D. (2020). Analisa Strategi Marketing Mix Menggunakan Konsep 4p (Price, Product, Place, Promotion) Pada Pt. Haluan Riau. Jurnal Teknik Industri: Jurnal Hasil Penelitian Dan Karya Ilmiah Dalam Bidang Teknik Industri, 5(2), 79. Https://Doi.Org/10.24014/Jti.V5i2.8997

Wijandari, A., \& Sumilah, N. (2021). Sosialisasi Manajemen Strategi Pemasaran Di Umkm Kecamatan Cileungsi. Jurnal Pengabdian Masyarakat Madani (Jpmm), 1(1), 61-64. Https://Doi.Org/10.51805/Jpbm.V1i1.12 